Temperature $100^{\circ}$. The muscles were still rigid. At 4 P.M. one-fifteenth of a grain of atropine was injected. At 11 P.M. temperature had risen to $103^{\circ} \mathrm{F}$. There was marked increase in the frequency and severity of the spasms. Again a fifteenth of a grain was injected, after which he was quite quiet for an hour. Later on he became restless, the spasms increasing, and attended with marked opisthotonos. The pupils were not dilated. A fifteenth of a grain was again injected, being three hours after the last. Temperature $105^{\circ}$. Next morning the patient was still restless, and had low muttering delirium and picking at the bedclothes. The pupils were dilated. Temperature $103^{\circ}$; pulse 120 ; respiration 36. He answered incoherently. The muscles were still rigid, but with much fewer and slighter exacerbations. Altogether one-third of a grain had been injected within the previous twenty-four hours. Atropine was discontinued.

From this time no more atropine was used. The delirium passed away in a few days. At first the tetanic spasms appeared to increase in severity, but it soon became apparent that the patient was slowly improving. The abdominal muscles, as usual, were the last to relax, but at the end of three weeks the man was practically well.

Remarks by Mr. ADAMS.-It is very difficult to say how much the atropine had to do with the recovery. Although not one of the most acute cases, it was undoubtedly one of considerable severity, and at the outset an unfavourable prognosis was given; still it is quite possible that recovery might have occurred, as in cases of chronic tetanus, independent of treatment. On the other hand, the patient, when not delirious, always expressed himself as being relieved by the injections, and those in immediate attend. ance on him reported him as being generally quieted by them for a short time.

The atropine treatment, hitherto but rarely used, seems at least worthy of more extended trial, and Mr. Adams suggests that it should be pushed until symptoms of poisoning are produced.

\section{LIVERPOOL WORKHOUSE HOSPITAL.}

FOUR CASES OF AMPUTATION THROUGH THE HIPJOINT ; REMARKS.

(Under the care of Mr. William Alexander.)

CASE 1.--James $\mathrm{F}$ - , aged seven years, was admitted May 28th, 1875, suffering from disease of the left thighbone, a part of which was lying bare amongst the glutei muscles. The disease had induced pyæmia, and the little patient lived in constant horror at the idea of being moved. Two years previously the patient had a fall, which excited coxalgia in the left hip. Excision was subsequently performed by a surgeon, but the wound not healing, he was sent into the workhouse hospital. Further examination revealed necrosis of the upper end of the femur for three inches, as well as necrosis of the acetabulum, and enlarged liver and spleen, For two months and a half rest, good feeding, \&c., were tried, only with the result that the patient was slowly but surely sinking. Accordingly, on August 25th, 1875, amputation was performed by anterior and posterior flaps. Scarcely an ounce of blood was lost, and the collapse was successfully combated by champagne. Next day all danger was over, the wound discharging profusely. The acetabular sequestrum separated in about six weeks, and at the end of six months the patient was sent to school strong and well.

CASE 2.-John W_- aged twenty-one, a carter, apparently in good condition, but an inveterate drunkard, was admitted some time in 1874, under the care of Mr. Alexander's predecessor, Mr. Barnes, suffering from coxalgia of right hip. Mr. Barnes excised it February 11th, 1875, with a good result for a time. The patient was readmitted towards the end of 1875, when Mr. Alexander re-excised it (April 5th, 1876) with a similar result to that on the previous occasion. As further excision did not offer any relief, amputation was performed January 20th, 1877. The shock was not severe, no blood was lost, and no champagne was required. The patient experienced much relief. Some acetabular sequestra came away, but the wound never healed completely. The man took his own discharge, although he had no friends to go to, and the result was that in a short time he came back dying from pneumonia, and in a most emaciated condition. His left ilium was a mere shadow of the opposite one, being affected with caries over its entire outer surface. He died eighteen months after the amputation.

CASE 3.-J. McC-, aged eight, was admitted on Oct. 11th, 1877, suffering from disease of the left hip-joint, the result of a fall. Excision was performed on May 8th, 1878, when both the acetabulum and the head of the femur were found extensively diseased. The patient rallied quickly after the operation, and the wound closed by the end of May. He was then attacked by lienteric diarrhoea, which went on for nearly two months, and was only checked by the administration of large doses of the liquid extract of bael. In October the wound reopened, a profuse discharge appeared, and exploration revealed extensive disease of the femur and acetabulum, much more extensive than the patient had any chance of resisting. Amputation was proposed, but rejected by the parents, on the plea that as the boy was nearly blind from a neglected ophthalmia, it was better for him to die than live with one leg. With their consent the operation was, however, performed on Oct. 23rd, 1878. The shock was severe, but gave way to champagne. The temperature, which, like the first case, had been ranging between $103^{\circ}$ and $99^{\circ}$, came down to normal on the 26th. Patient ultimately got fairly strong and healthy.

CASE 4.-Michael $\mathrm{C}-$ - aged eleven, was admitted January 31st, 1879, suffering from pain, tension, and swelling of left hip-joint. Temperature $103^{\circ}$; pulse 113 ; respiration 32. Disease caused by a fall on the ice a fortnight before. On February loth fluctuation was felt at outer side of thigh. An abscess was opened, and half a pint of sanious pus was evacuated; much relief was experienced thereby, On February 14th another abscess was opened on the inner side of the thigh. For the next three weeks pyæmic sym. ptoms, accompanied by signs of pneumonia in the left lung, prevailed; the temperature kept up to $103^{\circ}$ or $104^{\circ}$, and numerous fistulæ formed around the upper third of the femur. By the end of February the pneumonia had disappeared, the pyæmia had become chronic, and the appetite had improved, but the patient's strength was failing, owing to the great amount of suppuration. It was now proposed to amputate, but leave only was given to excise. Accordingly, on March 26th, 1879, excision was performed, but so much of the femur was diseased, the patient was so weak, and the tissues of the upper third of the thigh so infiltrated, that amputation was performed at the same time as the only chance of saving life. An hour after operation the tem. perature in the axilla was only $95^{\circ}$. By the frequent administration of small doses of champagne, in six hours it was $99^{\circ}$. A subcutaneous injection of three minims of morphia and atropine solution was then given. The patient slept soundly all night, and next morning the boy's face wore a very peaceful expression - a marked contrast to what it had been for weeks before. On the 29th his temperature was normal, and by the beginning of June was quite recovered, the stump being perfectly sound.

In all these cases amputation was performed by anteroposterior flaps, made by transfixing the limb.

Remarks.-Amputations through any part of the femur are still looked upon as capital operations, and amputations through the highest parts and through the hip-joint are worthy of being recorded not only on account of the dangers and difficulties of the operations themselves, but on account of the risk from shock that follows them. Quite recently, and on the assumption that much of the danger in operation arises from hæmorrhage during its progress, a plan has been adopted and an apparatus described and tried for pressing upon the iliac artery inside the pelvis. In some cases, by this method no blood has been lost, in others the plan has failed, and some say that inflammation may be the result of its use. In the above cases digital pressure in the usual way upon the artery as it passed over the brim of the pelvis, followed by pressure by the finger on any artery that sponted, until the operation was completed, was the method employed, and so effectually was it done that no serious amount of blood was lost in any case, and in most the loss only amounted to a few drops. The chief risk to life arises from the subsequent shock. That can, I believe, be most successfully treated by the judicious and frequent use of champagne. Having tried all the diffusible stimulants in such cases as the foregoing, champagne proved the most effectual. When reaction has set in, a morphia and atropine subcutaneous injection enables the patient to get over the distressful hours succeeding in a way the least hurtful and exhausting to his strength. These cases are the only ones of the kind that I have performed, and the fact that they 
were all successful may have led me to attach more than a just value to the plan of treatment followed. At any rate I offer them as a contribution to the statistics of the operation.

\section{THREE COUNTTES ASYLUM.}

$\triangle$ CASE OF HYDATID CYST IN THE WALL OF THE LEFT VENTRICLE OF THE HEART; RUPTURE OF THE CYST; SUDDEN DEATH.

Fon the notes of this rare and interesting case we are indebted to Mr. J. Stirling Buck, M.R.C.S., junior assistant medical officer.

A. S__-, male, aged eighteen years, a farm labourer, was admitted into the asylum on May 3rd, 1879, suffering from an attack of "mania" of seven days' duration, the probable eause of it being " hereditary," for his father and mother both died in an asylum. One brother died of heart disease.

On admission he was pale, delicate-looking, of fair com plexion, having a wild excited expression. The mucous membranes were anæmic. No physical examination of the thorax was made. He seemed in fair health, and com plained of no pain; he was usually tolerably well, excepting for slight occasional attacks of dyspepsia; there was no cedema or anasarca.

On May 4th he seemed well and progressing favourably, though excited, with some maniacal delusions. At 6.45 A.M. next day, when being dressed by an attendant, he suddenly fell down foaming at the mouth, and became intensely cyanotic about the face and extremities. Mr. Buck was at once sent for, and saw him five minutes after, when he was quite dead.

Necropsy, six hours after death.-Weather warm, bright, and dry. The tongue was between the teeth, but not bitten. The mouth was full of clear frothy fluid. The thumbs were not clenched into the palms of his hands. There was slight prominence of the right hypochondriac and lumbar regions of the abdomen, which were absolutely dull on percussion.There was no emaciation, and no other external marks. Head: The skull was rather thinner than usual; longitudinal sinus rather gorged with blood. The convolutions of the brain were well marked and of firm consistence; the vessels of the pia mater were gorged with blood, and three was slight excess of fluid in the ventricles; no signs of hrmorrhage could be discovered anywhere; weight of whole brain, $50 \frac{3}{2} 0 \mathrm{z}$; ; weight of cerebelium, $6 \frac{1}{2} \mathrm{oz}$. The lungs were quite healthy. The heart weighed 101 oz.; the mitral valves were healthy, but somewhat thickened; the tricuspid and semilunar were also healthy and rather thickened. In the wall of the left ventricle, near its apex, there was a cyst about the size of a pigeon's egg, which apparently had burst into the cavity of the ventricle, by a small aperture at the upper part of the cyst; to the hinder wall of the cyst, just below the point of rupture, there was a large chorda tendinea attached. On removing the cyst from the wall of the ventricle there was a large round cavity left with perfectly smooth walls. The muscular tissue of the wall of the ven tricle was very much thinned, both behind and in front of the cyst, so much so in front that for the space of about a half-crown it was entirely replaced by a rather thick and tough fibrous membrane. On examining a little of the scraping from the inner wall of the cyst under the microscope, echinococci were found. Three large cysts were also found in the liver, the largest in the left lobe, another in the lobus quadratus, and another smaller one in the anterior portion of the right lobe; the liver substance was normal. Microscopical examination of the contents of the cysts revealed plenty of echinococci. The other organs were perfectly healthy. There was no obstruction in the larynx or trachea.

\section{ADELAIDE HOSPITAL, SOUTH AUSTRALIA.}

REMOVAL OF HALF OF A NO. 7 GUM-ELASTIC CATHETER FROM THE MALE BLADDER BY LITHOTOMY.

(Under the care of Dr. Charles Gosse.)

W. HNov. 16th, 1878, with the following history. He had for some time past suffered with difficulty in passing his water, not from stricture, but from atony of the bladder, and had been in the habit of using an instrument for himself. On the day before his admission he passed his gum-elastic catheter as usual, but in withdrawing it found that only half appeared ; the remainder, he stated, had broken off in the bladder.

On admission a sound was passed into the bladder, but with uncertain results as regards the presence of a foreign body. Two days afterwards the sound was passed again, and all uncertainty removed. The patient's state indicating some considerable amount of pyrexia, on Nov. 20th, ether having been administered, he was examined by Dr. Gosse and his colleagnes. After a good deal of discussion, it was decided to operate as if for stone, and try to remove the half catheter.

The patient being placed in the lithotomy position, a Buchanan's staff (modified with the joint at an obtuse angle) was passed, and went in very easily, the patient having a spacious urethra. With one cut the groove in the staff was struck, and, the incision being continued, the bladder was entered with very great ease. The finger was then introduced into the bladder, and the first thing it came in contact with was the catheter, bent into the form of an oval; it was removed without using the forceps.

The lad made a somewhat protracted recovery, not leaving the hospital for six weeks, but the wound had perfectly healed by that time.

It should be added that the lithotrite was tried on two occasions, but, from the very nature of the substance in the bladder, there was some doubt whether the body had been touched or not. In this particular the case differs from one recorded in THE LANCET of Jan. 18th, 1879, of the removal of a clay pipe-stem by Mr. Rose, of King's College Hospital. In the present case it was deemed useless to persevere with the lithotrite, and recourse was had to the knife almost at once.

\section{OBSTETRICAL SOCIETY OF LONDON.}

ON Wednesday, Oct. 1st, the Obstetrical Society held its first meeting after the recess. The attendance was but scanty, owing to the fact that many of the schools had their opening meetings or dinners at the same hour. The following papers were read: Cholera in the New-born, by Dr. Lucas; Deficient Development of the Uterus, Atresia of the Os Externum, Atrophy of the Ovaries, by Mr. Alban Doran; Notes on an Acoustic Sign heard after the Death of the Foetus, by Dr. Harvey; a Case of Congenital Inguinoovarian Hernia, in which both Ovaries were removed, by Dr. T. Chambers.

This last case was that of a young woman twenty-four years of age. She had observed the swellings in the in guinal region as long as she could remember. She had never menstruated or experienced menstrual molimen. There was a small, short, conical vagina, at the top of which was the opening of the urethra. No uterus could be found by vaginal or rectal examination. The bodies in the groins were subject to pain and injury from knocks and blows, and it was determined to remove them, for they could not be pushed up into the cavity of the belly. When the patient was put under chloroform, however, one of these bodies ascended through the inguinal ring spontaneously. They were removed under carbolic spray, but the dressing of the wounds appears to have been imperfectly antiseptic; the wounds suppurated, but the patient completely recovered. The specimens removed were shown at a previous meeting of the Society, and were referred for report to a select committee consisting of Dr. Galabin and Dr. John Williams. Their report was read after the paper. Microscopic examination showed the bodies to be glandular organs, presenting, however, the structure, not of ovaries, but of imperfectly developed testicles. Sections were exhibited showing the small tubules of the testicle. The external characters of the organs, moreover, were those of the testicle. - In the discussion which followed, Dr. John Williams said he thought this case was one of the most valuable of the kind published, on account of the completeness of the history and of the anatomical examination of the specimens removed. It was difficult to understand how an ovary could enter a congenital hernia, while it was well known that the testicles naturally descended along the inguinal canal, and it was far more probable that all cases of supposed congenital hernia of the ovaries were really cases of undescended testicles.-Dr. Routh thought that the absence of the uterus could only be 